\title{
Infant and Under Five Mortality Rates in Nigeria: An Impact Analysis of Macroeconomic Conditions
}

\author{
Rahman Olanrewaju Raji ${ }^{1}$ \\ ${ }^{1}$ Canterbury International High School, Lekki-Ajah, Lagos, Nigeria \\ Correspondence: Rahman Olanrewaju Raji, Canterbury International High School, Lekki-Ajah, Lagos, Nigeria. \\ Tel: 234-802-309-7110. E-mail: rahman.raji@rocketmail.com/rahmandole@gmail.com
}

Received: March 1, 2020 Accepted: March 20, 2020 Online Published: March 26, 2020

\begin{abstract}
Over the years, the rising unfriendly macroeconomic environment is a contributing factor to the infant and underfive mortality rate in Nigeria. The study investigated the role of macroeconomic conditions on infant and underfive mortality rates in Nigeria for the period 1986-2017 using the fully modified OLS technique. The results show that the unfriendly macroeconomic policy environment such as the instability of inflation rate, unemployment and exchange rate enhanced the increased level of infant and under-five mortality rate in Nigeria. The study recommends that the authority should adopt more pro-growth policies that can ensure and maintain sound domestic macroeconomic policies to stem child mortality rate and promote economic growth through investment in food production and related investment in health. Most importantly, macroeconomic policies and institutions are highly needed to be strengthened in order to have a friendly macroeconomic environment which will in turn improve the population health of the country which can enhance sustainable and long term dietary as well as nutritional pattern of young age children and adult.
\end{abstract}

Keywords: infant mortality rate, under-five mortality rate, macroeconomic condition, fully modified OLS

\section{Introduction}

It is believed that the state should be responsible for the well-being of the people in other to avoid morbidity, mortality and hunger and not by mere possessions of commodities. According to Sen (1999), the mortality information throws light on the nature of social inequalities and economic inequalities including gender bias and racial disparities; biases in economic arrangements which result in deprivation and hardship in the society. In order to improve the quality of life in the society, performance on health care other than national outcomes and production yield is suggested to be an adequate indicator of the well-being of the society and the widely adopted indicator for the quality of life is the child mortality rate, including infant mortality.

As a result of the absence of or inadequate health care services associated with infant and child mortality; and the low income of individuals within a given society, accessing health care services become difficult for individuals, which ultimately lead to deterioration in the health status of individuals. The consequences of such health deterioration include high infant, child and maternal mortality, a rise in the death rate, decrease in life expectancy and the productive capacity of the people, absenteeism at work, low output, low income, and poverty. By implication, there is apparent relationship between the health status of a whole population and the quality of the environment which includes the socio-economic state, environmental issues and macroeconomic conditions of the country. For instance, mortality (infant mortality and child mortality) is one of the socioeconomic issues affecting the economic growth and development of developing countries where mostly child death took place. Such call for measure towards child mortality reduction which is one of the goals of the Millennium Development Goals (MDGs) now incorporated into Sustainable Development Goals stating that reduction of under-five mortality by two-thirds between 1990 and 2015 which is being extended till 2030 by ensuring healthy lives and promote well-being for all at all ages. According to UNICEF (1990) as well as Anand and Ravallion (1993), they argue that socioeconomic factors such family income, wealth, parental education and so on have effects on children survival including their health which fall under what is termed as proximate determinants of child survival (mother fertility pattern, environmental contamination, nutrient deficiency, injury and personal illness control) of Mosley and Chen's theory (1984) and that directly or indirectly these proximate determinants are influenced by macroeconomic conditions of an economy.

UNICEF (1990) reiterated that the political and ideological shapes of any society depend on economic structure 
which determines availability of resources, human control and economic set up. These imply that household food security, health services and care for children and women are affected by the availability of information and education level being determined by the economic and organization structures of the national economy. Christian (2010) enumerated the number of nutritional pathways by which the macroeconomic condition such economic crisis and increase in food prices may affect infant and child mortality and that food crisis and insufficient food availability can result to a rise in childhood wasting and stunting, intrauterine growth restriction, and micronutrient deficiencies which include vitamin A, iron, and zinc.

Studies like Gaiha et al (2012), Ferreira and Schady (2009) and Aguero and Valdivia (2010) established that unstable macroeconomic condition particularly during economic depression and recession has negative repercussion on children welfare which ultimately escalates rate of child and infant mortality via a fall in household real income where many families cut back on their expenditure for health as well as reduction in public health spending by the central authority or government. Increase in child morbidity and mortality has been associated with vulnerability of children to food insecurity, inadequate food intake together with unpleasant shifts in dietary and poverty which tend to affect both physical and mental development of children. This is as a result of unfavourable macroeconomic condition of society which includes high increase in food and drug prices, continuous fall in food production, fall in purchasing power of household, exchange rate volatility, uncertain and unfavourable economic policies. These suggest that unfriendly macroeconomic policy environment tends to impede sustainable and long term dietary and nutritional pattern of young age children which may impair proper mental development and learning ability of children such enhances a decrease in future work productivity.

In a nutshell, there seems to be strong consensus that macroeconomic environment has an impact on population health of the society particularly children survival through nutritional and dietary pattern of mothers during the inception of their pregnancies and the first one thousand days of their babies which are the most critical period for brain development, physical growth and the development of strong immune system, the quality and state of food security in the economy as well as health care services available for the teeming population. Due to these, there is a need for study towards finding the level of impact of macroeconomic conditions on population health especially mortality. However, in spite of various studies towards assessing determinants of infant, child and under five year mortality in developing countries particularly Sub-Saharan African countries, Studies like Adeyele and Ofoegbu (2013) examined infant and child mortality in Nigeria: an impact analysis using socio-economic variables, Abbuy (2018) studied macroeconomic determinants of infant mortality in WAEMU Countries: evidence from panel data analysis, Akinlo and Odusanya (2016) investigated effects of food prices on under-five and infant mortality rates in Sub-Saharan Africa, Cornia and Rosignoli (2011) conducted a study on the impact of food and financial crises on child mortality in Sub-Saharan Africa while Obayelu (2010) on global food price increases and nutritional status of Nigerians. In spite of the various macroeconomic challenges, there appears to be less emphasis on macroeconomic condition and population health particularly infant and child mortality in Nigeria. There is therefore paucity of empirical evidence on the relationship between macroeconomic condition and mortality of infant and children in Nigeria. Hence, this study is an attempt to fill the gap.

\section{Literature Review}

An unfriendly and unconducive macroeconomic environment tend to have an adverse effect on household food security leading to undermining of population health which in turn can retard level of human development and consequently lower labour productivity and efficiency of the economy if not in short run but in long run. Among the leading factors to be considered influencing the population health proxy by infant and child mortality rate is the impact of macroeconomic condition in an economy. Few studies are country specific time series based and some are panel data analysis based like Abbuy (2018), Baird et al. (2011), Bourne (2012) Anderson et al. (2011), Renton et al. (2012), Akinlo et al. (2016), Lee et al. (2013).

Abbuy (2018) assessed the macroeconomic determinants of infant mortality in WAEMU countries for the period 1980-2016 using fixed effects instrumental variables estimator in panel data model. The conclusion was that GDP per capita and public health expenditure had significant and asymmetric relationship with infant mortality in the region and also, female literacy and urbanization significantly affected infant mortality rate in a negative way. Baird et al. (2011) attempted to investigate the relationship between macroeconomic contractions and infant survival in low and middle income countries. Their findings indicated that there was significant and statistically robust relationship between GDP per capita fluctuation and infant mortality rate. In developing countries, whenever there was negative economic shocks, infant especially girls were more likely to die, on average, a one per cent decrease in GDP per capita resulted in an increase in infant mortality from 0.24 to 0.40 per 1,000 children born. 
Akinlo et al(2016) examined the impact of rising food prices on under-five and infant mortality rates in 31 selected sub-Saharan African countries for the period 2001-2012 using the fixed effects, random effects, difference GMM and the system GMM. The results showed that rising food prices exert significant adverse effects on both infant and under-five mortality rates in Sub-Saharan Africa. This finding was consistent with Lee at al (2013) that employed a panel dataset covering 63 developing countries from 2001 to 2010 to assess the effects of food price inflation and volatility on population health proxies by infant mortality rate, child mortality rate, and the prevalence of undernourishment. Findings indicated that rising food prices had a significant and adverse effect on all three health indicators in developing countries

Bourne (2012) studied the impact of macroeconomic variables on infant and child mortality with regard to the English-speaking Caribbean using Ordinary least square regression. The outcome of study showed that health care utilization and infant mortality rate had positive and significant relationship while poverty level was a factor influencing child mortality rate but during economic crisis infant and child mortality rates declined.

Pritchett and Summers (1996) examined the effect of income on child mortality in developing countries where finding revealed that increase in income indeed led to better health in terms of improved infant as well as child mortality; after controlling for education implying that a country at the sample mean would avert 1 death per 1000 if income were 1 percent higher.

Anderson et al. (2011) used descriptive analysis to assess how economic shocks, including the global financial crisis of 2008/2009, affected the poor in developing countries over the period 2000-2010, focusing particularly on vulnerable children in 19 developing Asia countries. They concluded that despite there was much progress had occurred in Asia, there remained some very high burdens of newborn and child mortality and morbidity and inability to reduce these levels further during rapid economic growth makes them vulnerable to slower progress during a global crisis-induced slowdown. Anderson et al. (2011) was similar to Renton et al. (2012) who analyzed the relationship between economic growth and some health indicators including the rate of child mortality. They considered 102 developing countries through cross-sectional time-series regression analysis using a random effect model. Although, their findings were not sufficient to assert that economic growth caused health improvements and therefore reduced child mortality.

Based on time series analysis for instance, Seid (2012) sought to analyze the impact of macroeconomic condition on infant survival in Ethiopia. The result indicated that macroeconomic condition had insignificant impact on child health rather the micro level variables were found to be the most important determinants such behavioral factors, maternal, environmental and socioeconomic factors play crucial role

Ang (2017) examined the effects of the economic determinants to child mortality in Philippine. The results from the food price inflation rate and child mortality exhibited an insignificant relationship but out-of-pocket and government expenditures were proven to be statistically significant in the reduction of child mortality.

Paxson and Schady (2004) investigated the impact of macroeconomic shocks on infant mortality rate in Peru using Demographic and Health Survey (DHS) data with macroeconomic variable (GDP). It was found out that infant mortality increased in times of deep economic crisis in Peruvian case which was attributed to the collapse in both private and public health expenditure in such economic conditions. Consistent with Paxson and Schady (2004) using Peruvian data, Aguero and Valdivia (2009) found that decline in GDP per capita led to increase in infant mortality; 1 percent declined in GDP per capita was associated with an increase in infant mortality between 0.30 and 0.39 percent.

Bhalotra (2007) investigated the impact of macroeconomic shocks on childhood mortality in India. The income of the study showed that temporary downturns in the economy raise mortality and that policies that increase growth rate of the agricultural sector would contribute to the reduction in infant and child mortality.

In conclusion, there is consensus from studies that unfriendly and un-conducive macroeconomic parameters always tends to have adverse effects on population health in term of increasing malnutrition, rising the rates of infant and under-five mortality and even fall in life expectancy of people in the society. In short, most studies focused on food inflation price, economic downturn and financial depression on population health without assessing the role of CPI inflation, exchange rate, female unemployment rate and even interaction of inflation and exchange rate on population health (infant mortality, child mortality and life expectancy) of society.

\section{Research Method}

\subsection{Specification and Estimation Method}

To examine uncertainty surrounding current and future direction of macroeconomic environment have any impact on infant and child mortality in Nigeria, this paper draws on a similar model by taking cue from previous studies 
(Ruhm, 2004, Lee et al. 2013, Freire and Kajiura, 2011 among others) and estimate a dynamic time series data model where the health outcomesis a function of macroeconomic condition or environment and control variables as:

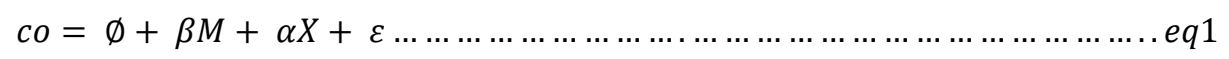

Where Co is the mortality rate, $M$ represents macroeconomic environment, $X$ is a vector of control variables and $\epsilon$ is the error term. $\beta$ and $\alpha$ are the coefficients of $\mathrm{CO}, \mathrm{M}$ and $\mathrm{X}$ respectively. This study considers female unemployment (une), cpi inflation rate (inf), exchange rate(exch), GDP per capita ( $g d p p$ ) and interaction of CPI inflation and exchange rate (infexch) as macroeconomic condition. Also, government health care expenditure (hce), out of packet purchase (opp) and food production index (fpi) are chosen as the control variables for the study. These variables are chosen as a result of carefully examining the theoretical and empirical literature. Therefore $M$ and $X$ can be re-written as:

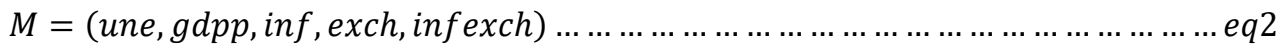

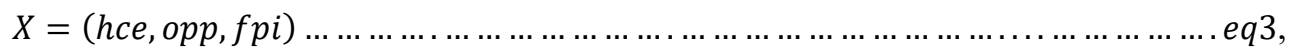

Replacing equation (2) and (3) into equation (1) and specifying an extended form of the equation, the empirical model of the study can be re-written as;

$$
\begin{aligned}
& \mathrm{CO}_{\mathrm{t}}=\emptyset+\beta_{1} \text { une }_{\mathrm{t}}+\beta_{2} \text { gdpp }_{\mathrm{t}}+\beta_{3} \text { inf }_{t}+\beta_{4} \text { exch }_{t} \beta_{5} \text { infexch }_{\mathrm{t}}+\alpha_{1} \text { hce }_{\mathrm{t}}+\alpha_{2} \mathrm{opp}_{\mathrm{t}}+\alpha_{3} f p i_{t}
\end{aligned}
$$

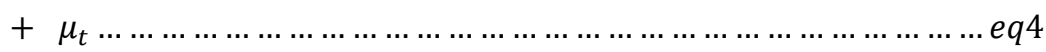

In $\log$ expression,

$$
\begin{aligned}
& \log \mathrm{CO}_{\mathrm{t}}=\varnothing+\beta_{1} \operatorname{logune}_{\mathrm{t}}+\beta_{2} \operatorname{loggdpp_{\mathrm {t}}}+\beta_{3} \operatorname{loginf}+\beta_{4} \operatorname{logexch}_{t}+\beta_{5} \operatorname{loginfexch}_{\mathrm{t}}+\alpha_{1} \text { loghce }_{\mathrm{t}} \\
& +\alpha_{2} \operatorname{logopp} p_{t}+\alpha_{3} f p i_{t}+\mu_{t} \ldots \ldots \ldots \ldots \ldots \ldots \ldots \ldots \ldots \ldots \ldots \ldots \ldots \ldots \ldots \text { eq } 5
\end{aligned}
$$

Therefore,

$$
\begin{gathered}
\Delta\left(\log \mathrm{CO}_{\mathrm{t}}\right)=\varnothing+\Delta\left(\beta_{1} \operatorname{logune}_{\mathrm{t}}\right)+\Delta\left(\beta_{2} \operatorname{loggdpp}_{\mathrm{t}}\right)+\Delta\left(\beta_{3} \operatorname{logfinf}_{t)}+\Delta\left(\beta_{5} \operatorname{logexch}_{t)}+\Delta\left(\beta_{5} \operatorname{loginfexch}_{\mathrm{t}}\right)\right.\right. \\
+\Delta\left(\alpha_{1} \operatorname{loghce_{\mathrm {t}}}\right)+\Delta\left(\alpha_{2} \operatorname{logopp}_{\mathrm{t}}\right)+\Delta\left(\alpha_{3} \operatorname{logfpi}_{t}\right)+\mu_{t} \ldots \ldots \ldots \ldots \ldots \ldots \ldots \text {...... } 6
\end{gathered}
$$

Eq.6 was estimated using fully modified ordinary least squares in order to account for endogeneity among regressors.

\subsection{Data Sources}

The study is carried out on Nigeria for the period 1986 and 2017 using annual data. The data used are all sourced from World Development Indicators (WDI), World Bank and Central Bank of Nigeria database.

\section{Empirical Results}

\subsection{Result Analysis}

The table 1 shows the results of the fully modified ordinary least squared estimation with regard to the baseline, the impact of macroeconomic condition variables on infant mortality and under five mortality rates without control variables, all the coefficients are significant except current exchange rate. It implies that current exchange rate does not seem to an impact on both mortality rates. The coefficients of female unemployment and CPI inflation are found to be positive and highly significant. A percent increase in female unemployment enhances both infant mortality rate and under five mortality rate by $0.008017 \%$ and $0.010073 \%$ respectively. Similarly, a percent increase in contemporaneous CPI inflation rate leads to $0.011510 \%$ and $0.013991 \%$ increase in infant mortality and under five mortality rates respectively. Effect of GDP per capita and a lag of exchange rate are negative and significant. A one percent rise in GDP per capita mitigates the rate of infant mortality and under five mortality rates by 0.003304 percent and 0.002907 percent respectively. In similar vein, an increase in one lag of exchange rate by a percent ensures a decline in infant mortality and under five mortality rates by 0.004111 percent and 0.004718 percent. The coefficient of the interaction of CPI inflation rate and exchange rate is found to be negative for both mortality rates. This shows that as the interaction of inflation and exchange rate improves infant mortality and under-five mortality rate decline. This suggests that CPI inflation reduces the impact of exchange rate on both mortality rates in Nigeria. Finally, infant and under five mortality are highly persistent as the positive coefficient of the lagged value is close to one and significant. Among all the macroeconomic condition variables, both mortality rates are more sensitive and more responsive to CPI inflation. 
Table 1. Macroeconomic Condition only and IMR/U5MR

\begin{tabular}{ccc}
\hline & \multicolumn{1}{c}{ IMR } & \multicolumn{1}{c}{ U5MR } \\
$\mathbf{2}$
\end{tabular}

Note: the missing observations were generated based on normal imputation techniques, since the missing values are assumed to be linear functions of other observed values. For details see, (i) Honaker and King (2011) "Application of Modern Methods for Analysing Data with Missing Values based primarily on Multiple Imputations and Weighting Approaches" (ii), Maravall and Pena (2014) "Missing Observations and Additive Outliers in the Time Series Models: Interpolation using ARIMA processes.

Table 2 displays the outcomes of the fully modified OLS technique when control variables were added to the macroeconomic condition variables to estimate the dependent variables, infant mortality and under-five mortality rates in Nigeria. In this case, the GDP per capita variable is negative which is no longer significant in favor of certain control variables because the variable is highly correlated with other control variables in the model while current exchange rate and one lag of exchange rate are positive and highly significant as a result of certain control variables are not too correlated with exchange rate. The effects of female unemployment, CPI inflation and interaction of inflation and exchange rate variables do have consistent outcomes in all specifications from table 1 and 2 after additional variables were introduced. Concerning food production index, the results reveal a statistically significant influence on the infant mortality and under five mortality rates, whereby a larger percentage of food production index tends to reduce infant and under five mortality rates in Nigeria. Government health expenditure is negatively and significantly associated with infant mortality and under-five mortality rates, indicating that government's commitment to public health plays an important role in improving the rate of decline in infant mortality and under-five mortality in Nigeria. The coefficient of one lag effect of out-of-pocket expenditure is negatively and significantly associated with under-five mortality rate but absence of significant relationship with infant mortality rate meaning that out-of-pocket expenditure seems not to have impact on infant mortality in Nigeria. It implies the increasing out-of-pocket expenditure reduces under-five mortality rate. Higher out-ofpocket expenditure created the capability to access one's necessary needs with quality.

Table 2. Macroeconomic Condition and Control Variables on IMR/U5MR

\begin{tabular}{|c|c|c|}
\hline & IMR & U5MR \\
\hline $\log$ (une mployment) & $0.014123(2.155613)^{* *}$ & $0.023869(4.036856)^{* * * *}$ \\
\hline $\log ($ inflation$)$ & $0.139958(3.981539)^{* * *}$ & $0.187529(5.914016)^{* * *}$ \\
\hline $\log ($ Exchange Rate $)$ & $0.070920(3.987439)^{* * *}$ & $0.093807(5.849371)^{* * *}$ \\
\hline log(Exchange Rate $(-1)$ & $0.024882(2.385498)^{* * * *}$ & $0.022250(2.372146)^{* * *}$ \\
\hline $\log$ (inflation $*$ Exchange Rate) & $-0.029186(-4.058047) * * *$ & $-0.038966(-6.005828)^{* * *}$ \\
\hline $\log (\mathrm{GDP})$ & $-0.003786(-0.945070)$ & $0.001484(0.410524)$ \\
\hline $\log (\operatorname{IMR}(-1) / \log (\mathrm{U} 5 \mathrm{MR}(-1)$ & $0.998234(49.55768)^{* * *}$ & $1.021459(63.38360)^{* * *}$ \\
\hline $\log ($ Food Production Index $)$ & $-0.014755(-1.946044)^{* *}$ & $-0.013951(-2.033034)^{* *}$ \\
\hline $\log ($ Health Expsnditure $)$ & $-0.004770(-1.844489)^{* *}$ & $-0.005023(-2.151773)^{* *}$ \\
\hline $\log ($ Out - Pocket Purchase $(-1))$ & $-0.006676-(0.609615)$ & $-0.017165(-1.733754)^{*}$ \\
\hline $\mathrm{C}$ & $-0.366274(-2.154424)^{* *}$ & $-0.619675(-4.066619) * * *$ \\
\hline Long Run Variance & 7.26 & 5.91 \\
\hline
\end{tabular}




\subsection{Discussion of Findings}

The evidence presented in this article suggests that some of macroeconomic condition variables are extremely costly. The increase in the number of infants and under-five children dying during unfriendly macroeconomic conditions may not seem very large when compared to the population of the country, Nigeria. It is very substantial to be aware that infant mortality and under five mortality are not rare event in this country. A 0.008017 increase in infant mortality and a 0.010073 in increase under-five mortality during female unemployment crisis; during inflation crisis, a 0.011510 increase in infant mortality and a 0.013991 increase in under-five mortality are not easy events to ignore in an economy.

The coefficient of female unemployment shows positive relationship with infant and under-five mortality rates. It implies that the increase in infant and child mortality can be linked to female unemployment in the society. Inabilities of nursing mothers and women to have access to basic social and economic needs of life as a result of inadequate employment opportunity, poor income payment, job insecurity, food insecurity and related matters that can improve maternal situations in the society tend to escalate the rate of mortalities in the country. Measures should be in place for women and nursing mothers to have access to resources, extending assistance in term of maternal care financing, eradication employment discrimination again nursing mothers and so on.

The coefficient of CPI is positive which suggests that when the cost living increases, living condition gets deteriorated and as the result mortality tends to increase in such bad economic times such is consistent with previous empirical works in developing countries (Bhalotra, 2007; Schady and Smith, 2009). An increase in CPI inflation rate leads directly to a decline in real purchasing power and makes households worse-off. In response to higher CPI inflation rate, households adjust or reshuffle their food and non-food budgets, by substituting more expensive nutritious food items and other needs of improving living standard for cheaper and less nourishing foods and other basic necessity of life (Schnepf, 2013). The result also shows interaction term (inflation and exchange rate) enters with negative coefficient while the coefficient of current exchange rate seems not to have impact and its lag value coefficient indicates negative effect on both mortality rates. The impact of exchange rate on mortality rates varies with the level of CPI inflation rate. It implies that there is a tendency that moderate CPI inflation would ensure an improvement in the level of foreign exchange rate which in turn could mitigate the rates of child mortality in the economy.

Higher improvement in the level of income has the tendency of mitigating the rate of infant mortality and underfive mortality rates in Nigeria. It implies that increasing the incomes of particularly the rural poor which can improve level of their consumption and accompanied with subsidies for the benefits of the urban poor which can reduce the state of food-deficiency. In addition, government should put in place social budgets and provision of adequate protection for vulnerable children as well as measures to break the cycle of poverty in the society and where there is a set of consumers with more vulnerable to the impact of the rising prices of basic necessity life should be urgently provided safety nets.

Per capita government health care expenditure has found to have serious implications on infant mortality rate and under-five mortality rate in Nigeria. Empirical findings revealed per capita government health expenditure has a strong negative relationship with infant mortality rates and under-five mortality rates. By implication, increased government spending or investments in public health are stemming mortality rates and under-five mortality rate.

Moreover, improvement in food production has a significant negative association with infant mortality rate and under-five mortality rates in Nigeria. This indicates that government and private individuals should massively invest in food production and related area like agriculture in through expansion in public spending covering rural infrastructural development, extension services, research and development as well as availability of basic inputs to farmers which can improve their farming activities in the economy. In addition, investment policy measures should ensure curtailment of the menace of climatic change and including attraction of more both domestic and foreign investors into agriculture, reduction of rural-urban drift and improvement of farm yield and profitability.

Surprising, improvement in out of packet expenditure has a significant negative association with infant mortality rate. Financing healthcare indicates households are paying some shares of their income for healthcare in Nigeria. A 0.017165 decrease in under-five mortality rate in Nigeria due to one percent improvement in out-of packet expenditure is a great implication to the economy and future labour participation. It can mean that children who are below under-five in a family who access to health services are more unlikely to obtain diseases and die at their younger age.

\section{Concluding Remarks}

Our study adopted fully modified OLS method to examine the impacts of macroeconomic conditions on 
infant/child mortality in Nigeria; the study discovered that macroeconomic condition parameters such as female unemployment, foreign exchange rate and CPI inflation have significant and enhancing effects on infant and underfive mortality. Our results show that GDP per capita, improving interaction between inflation and exchange rate, health care expenditure, food production and out of packet expenditure help to reduce child mortality in Nigeria. The results further remain essential for government in Nigeria and monetary authority to initiate economic policies that will mitigate the effects of CPI inflation and foreign exchange rates in the economy.

Moreover, once a society fails to establish a better and improved political and ideological institutions which depend on economic institution or structure that dictates the direction of available resources, human control and economic set up in the country, a friendly macroeconomic condition might be difficult to be achieved. This tends to have adverse implications on population health which includes high increase in food and drug prices, continuous fall in food production and fall in purchasing power of household, exchange rate volatility, uncertain and unfavourable economic policies. This suggests that unfriendly macroeconomic policy environment tends to impede sustainable and long term dietary and nutritional pattern of young age children which may impair proper mental development and learning ability of children such enhances a decrease in future work productivity

\section{References}

Abbuy, E. K. (2018). Macroeconomic Determinants of Infant Mortality in WAEMU Countries: Evidence from Panel Data Analysis. Applied Economics and Finance, 5(6). https://doi.org/10.11114/aef.v5i6.3682

Adeyele, I. T., \& Ofoegbu, D. I. (2013). Infant and Child Mortality in Nigeria: An Impact Analysis. International Journal of Economic Practices and Theories, 3(2).

Agüero, J. M., \& Valdivia, M. (2010). The Permanent Effects of Recessions on Child Health: Evidence from Peru. Estudios Económicos, 25(1), 247-274.

Akinlo, A. E., \& Odusanya, I. A. (2016). Effects of Food Prices on Under-five and Infant Mortality Rates in SubSaharan Africa. African Journal of Economic Review, IV(1).

Anand, S., \& Ravallion, M. (1993). Human Development in Poor Countries: On the Role of Private Incomes and Public Services. Journal of Economic Perspectives, 1(3), 133-150. https://doi.org/10.1257/jep.7.1.133

Anderson, I., Axelson, H., \& Tan, B. K. (2011). The other crisis: The Economics and Financing of Maternal, Newborn and Child Health in Asia. Health Policy and Planning, 26, 288-297. https://doi.org/10.1093/heapol/czq067

Ang, Cruz., Pural., \& Rosete. (2017). The Economic Determinants of Child Mortality in the Philippines: A Panel Analysis of 16 Regions. Review of Integrative Business and Economics Research.

Baird, S., Friedman, J., \& Schady, N. (2009). Aggregate Income Shocks and Infant Mortality in the Developing World. Policy Research Working Paper 4346 The World Bank: Washington; 2007.

Balhotra, S. (2007). Fatal fluctuations? Cyclicality in infant mortality in India, IZA 2007; Discussion Paper No. 3086.

Bourne, P. A. (2012). Under-Five Mortality, Health and Selected Macroeconomic Variables: The Children behind the Digits. Epidemiology Open Access. https://doi.org/10.5455/jbh.20120426083928

Christian, P. (2010). Impact of the Economic Crisis and Increase in Food Prices on Child Mortality: Exploring Nutritional Pathways. The Journal of Nutrition, 140, 177-181. https://doi.org/10.3945/jn.109.111708

Cornia, G. A., Rosignoli, S., \& Tiberti, L. (2011). The Impact of The Food and Financial Crises on Child Mortality: The Case of Sub-Saharan Africa, UNICEF Innocenti Research Centre.

Freire, C., \& Kajiura, N. (2011). Impact of Health Expenditure on Achieving the Health-Related mdgs. MPDD Working Papers Macroeconomic Policy and Development Division.

Friedman, Jed, \& Norbert, S. (2009). How Many More Infants are Likely to Die in Africa as a Result of the Global Financial Crisis? Unpublished manuscript, The World Bank. https://doi.org/10.1596/1813-9450-5023

Gaiha, R. (2012). On hunger and child mortality in India, Journal of African Economies, 47(1), 3-17. https://doi.org/10.1177/0021909611427015

Lee, S., Lim, J., Lee, H., \& Park, C. (2013). Food prices and Population Health in Developing Countries: An Investigation of the Effects of the Food Crisis Using a Panel Analysis. ADB Economics Working Paper Series No. 374. Manila, Philippines: Asian Development Bank. https://doi.org/10.2139/ssrn.2323143

Mosley, W. H., \& Chen, L. C. (1984). An Analytical Framework for the Study of Child Survival in Developing 
Countries. Population and Development Review, 10, 25-45. https://doi.org/10.2307/2807954

Obayelu, A. E. (2010). Global Food Price Increases and Nutritional Status of Nigerians: The Determinants, Coping Strategies. Policy Responses and Implications, ARPN Journal of Agricultural and Biological Science. Asian Research Publishing Network (ARPN).

Paxson, C., \& Schady, N. (2010). Does Money Matter? The Effects of Cash Transfers on Child Development in Rural Ecuador. Economic Development and Cultural Change, 59(1), 187-229. https://doi.org/10.1086/655458

Renton, A., Wall, M., \& Lintott, J. (2012). Economic Growth and Decline in Mortality in Developing Countries: An Analysis of The World Bank Development Datasets. Public Health, 26, 551-560. https://doi.org/10.1016/j.puhe.2012.03.011

Ruhm, C. L. (2004). Macroeconomic Conditions, Health and Mortality NBER Working Paper Series. Retrieved from http://www.nber.org/papers/w11007 https://doi.org/10.3386/w11007

Schnept, R. (2013). Consumers and Food Price Inflation, Congressional Research Service Report, R40545, The Us Congress.

Seid, E. S (2012). Macroeconomic Conditions and Infant Mortality. In Ethiopia: A Survival Analysis, Lund University (School of Economics and Management) unpublished Research Mater Thesis.

Sen, A. (1999). Development as Freedom, Oxford University Press.

Summers, L. H., \& Pritchett, L. (1996). Wealthier is healthier. J Human Resources, 31(4), 841-868. https://doi.org/10.2307/146149

United Nations Children's Fund (UNICEF). (1990). Strategy for Improved Nutrition of Children and Women in Developing Countries. New York: UNICEF.

\section{Copyrights}

Copyright for this article is retained by the author(s), with first publication rights granted to the journal.

This is an open-access article distributed under the terms and conditions of the Creative Commons Attribution license (http://creativecommons.org/licenses/by/4.0/). 